\title{
Contemporary Assessment and Pharmacotherapy of Tourette Syndrome
}

\author{
Lawrence Scahill, Gerald Erenberg, Cheston M. Berlin Jr, Cathy Budman, Barbara J. Coffey, \\ Joseph Jankovic, Louise Kiessling, Robert A. King, Roger Kurlan, Anthony Lang, \\ Jonathan Mink, Tanya Murphy, Samual Zinner, and John Walkup
}

Tourette Syndrome Association Medical Advisory Board: Practice Committee

\begin{abstract}
Summary: To develop a guide to clinical assessment and pharmacotherapy for children and adults with Tourette syndrome (TS), we reviewed published literature over the past 25 years to identify original articles and reviews on the assessment and pharmacological treatment of Tourette syndrome, attention-deficit/hyperactivity disorder (ADHD) and obsessivecompulsive disorder (OCD). The literature search also included a survey of reviews published in book chapters. The assessment section was compiled from several reviews. Pharmacological treatments were classified into those with strong empirical support (as evidenced by two positive placebo-controlled studies
\end{abstract}

for tics, OCD, or ADHD in TS samples); modest empirical support (one positive placebo-controlled study), or minimal support (open-label data only). We conclude that accurate diagnosis, including identification of comorbid conditions, is an essential step toward appropriate treatment for patients with TS. In many patients with TS, symptom management requires pharmacotherapy for tics or coexisting conditions. The evidence supporting efficacy and safety for medications used in patients with TS varies. But this evidence offers the best guide to clinical practice. Key Words: Tourette syndrome, ADHD, OCD, pharmacotherapy.

\section{INTRODUCTION}

Tourette syndrome (TS) is a movement disorder of childhood onset defined by the presence of motor and phonic tics. In addition to tics, TS is frequently associated with obsessive-compulsive symptoms, inattention, impulsive behavior, and motor restlessness. ${ }^{1,2}$ The tics of TS show a wide spectrum from mild to severe. Impaired adaptive functioning in TS may be related to tics or the presence of associated conditions such as attention-deficit/hyperactivity disorder (ADHD), obsessive-compulsive disorder (OCD), learning disabilities (LD), and other behavioral difficulties. In many cases, these co-occurring disorders may be of greater clinical importance than the tic symptoms. The impact of TS on family members, educational progress, occupational performance, or peer relationships can be substantial. Thus, clinical management of TS requires attention to severity of tics, associated features, response to the chronic illness, and overall functioning.

Address correspondence and reprint requests to Lawrence Scahill, M.S.N., Ph.D., Yale Child Study Center, 230 South Frontage Road, P.O. Box 207900, New Haven, CT 06520. E-mail: lawrence. scahill@yale.edu.
Accurate diagnosis, including identification of comorbid conditions, is an essential step toward appropriate treatment for patients with TS. Clinical care of TS involves education of the patient and family, advocacy in school and occupational environments, as well as symptom management. In many patients with TS, symptom management requires pharmacotherapy for tics or coexisting conditions. The clinical evidence supporting efficacy and safety for medications used in patients with TS varies. But this evidence offers the best guide to clinical practice and identifies areas for future research. In addition to medication interventions for patients with TS, OCD, and TS accompanied by ADHD, there are behavior treatments with different levels of empirical support $\left(\mathrm{see}^{3-6}\right.$ for reviews). For example, promising preliminary results suggest that a behavioral intervention based on habit reversal training may be beneficial for tics. ${ }^{7}$ Other nonpharmacological interventions include psychosurgery and deep brain stimulation. ${ }^{8,9}$ These interventions will not be included in this report.

\section{Diagnosis of TS and assessment of tics}

The initial assessment of a patient referred to the medical setting for a tic disorder includes a review of the 
TABLE 1. Classification of Tic Disorders*

Transient tic disorder, chronic tic disorder, Tourette syndrome: common features

- Onset before age 18

- Cannot be explained by another medical condition (e.g., substance abuse, Huntington's disease)

- Definite diagnosis: Motor and/or phonic tics must be witnessed by a reliable examiner directly at some point in the illness or viewed on a video recording.

- Diagnosis by history: Tics not witnessed by a reliable examiner, but tics were witnessed by a reliable family member or close friend, and the description of tics is accepted by reliable examiner.

Tourette syndrome: defining features

Both multiple motor and one or more phonic tics have been present at some time during the illness (concurrent motor and phonic tics not required).

- Tics occur many times a day, nearly every day, or intermittently throughout a period of more than a year.

- The anatomic location, number, frequency, complexity, type, and severity of tics changes over time.

Chronic multiple motor tic or phonic tic disorder: defining features

Either multiple motor or phonic tics, but not both, have been present at some time during the illness.

- The tics occur many times a day, nearly every day, or intermittently throughout a period of more than a year.

- The anatomic location, number, frequency, complexity, or severity of tics changes over time.

Transient tic disorder: defining features

Multiple motor and/or phonic tics.

- The tics occur many times a day, nearly every day for at least 2 weeks, but not for longer than 12 consecutive months.

* Modified from $\mathrm{REF}^{15,16}$.

early developmental history, medical history, onset and course of tics, and associated problems. A thorough evaluation of how the symptoms affect family, friends, school, and workplace is essential for gauging the impact of TS on the patient. Given the high likelihood of a genetic contribution, a thorough family history of tics, ADHD, obsessive-compulsive symptoms, and chronic medical, psychiatric, or neurological conditions is also warranted.

Diagnosis of a tic disorder relies on the history as well as on direct clinical observation (Table 1). The clinical interview should include assessment of:

- Onset and course of symptoms,

- Current severity of motor and phonic tics,

- Presence of premonitory sensations and capacity for tic suppression,

- Overall burden caused by the tics, and

- Treatment approaches implemented to date.

One challenge in the assessment of tic disorders is establishing the distinction between tics and behavioral symptoms. Clinician-family dialogue can establish a common vocabulary about the tics, promote a clear description of the symptoms, and tease apart tics from compulsions and impulsive behavior. Other diagnostic considerations include:

- There is no laboratory test for the diagnosis of a tic disorder. The diagnosis is based on the enduring presence of motor and vocal tics and exclusion of other explanations. Selective laboratory tests to rule out other medical problems are listed in Tables 1 and 2.

- In addition, except for the presence of tics, the standard neurological examination is usually normal.

- Further diagnostic and severity assessments may include symptom checklists completed by the patient, parent, and/or teacher ${ }^{10,11}$ and/or clinicianbased measures. ${ }^{12,13}$

TABLE 2. Selected Conditions with Shared Features of TS and Laboratory Tests Used for the Diagnosis

\begin{tabular}{|c|c|c|}
\hline Disorder & Shared Symptom Picture & Laboratory Test \\
\hline Huntington's disease & Chorea, clonic and dystonic tics & $\geq 35 \mathrm{CAG}$ repeat on DNA analysis \\
\hline Neuroacanthocytes & $\begin{array}{l}\text { Mouth movements, lip biting, dystonias, } \\
\text { motor and phonic tics }\end{array}$ & $\begin{array}{l}>15 \% \text { red blood cells as acanthocytes, elevated } \\
\text { serum creatine kinase }\end{array}$ \\
\hline Wilson's disease & Dystonia and dystonic tics & $\begin{array}{l}\text { Lowered blood ceruloplasmin, elevated urine copper, } \\
\text { Kayser-Fleisher rings on ophthalmological } \\
\text { examination }\end{array}$ \\
\hline Sydenham's chorea & Chorea, tic-like movements & $\begin{array}{l}\text { Evidence of a Group A } \beta \text {-hemolytic streptococcal } \\
\text { infection (preceding } 2-6 \text { months) }\end{array}$ \\
\hline Drug induced & $\begin{array}{l}\text { Motor and phonic tics, mouth } \\
\text { movements }\end{array}$ & $\begin{array}{l}\text { Recent history of stimulant drug use, may be } \\
\text { positive toxicology screen }\end{array}$ \\
\hline Developmental disorders & $\begin{array}{l}\text { Stereotypic movements, tic-like } \\
\text { mannerisms }\end{array}$ & $\begin{array}{l}\text { History of multiple delays in language, socialization, } \\
\text { cognition }\end{array}$ \\
\hline Head trauma & Motor and phonic tics & $\begin{array}{l}\text { Recent history of head trauma (preceding } 2 \text { weeks to } \\
6 \text { months) }\end{array}$ \\
\hline
\end{tabular}


Symptom checklists completed by the adolescent or adult patient or by a parent of a younger child may be useful to document the frequency, intensity, and interference of tics or behavior problem. However, these assessments are vulnerable to patient or parent biases regarding symptom classification and completeness. Therefore, tic ratings based on direct interview and observation by an experienced clinician is usually considered the gold standard for diagnosis and measure for tic severity. Although not unique to TS, most patients with TS describe premonitory sensations that precede tics and report some capacity to suppress their tics for brief periods of time. ${ }^{2,14}$

Medical tests to detect or evaluate the severity of tics are rarely used. For example, in rare cases, neurophysiological investigation may be helpful in differentiating tics from seizures, myoclonus, and psychogenic movement disorders. ${ }^{17}$ EEG is not needed unless the patient manifests episodic, paroxysmal alteration of consciousness or other features suggestive of a seizure disorder. Videotelemetry with combined EEG and EMG recording is not indicated in the evaluation of TS except when attempting to evaluate a sleep disorder $\left(\mathrm{see}^{18}\right.$ for review). ${ }^{19}$ Although differences in brain volumes and dopamine function between patients with TS and normal controls have been demonstrated in neuroimaging studies, ${ }^{20-22}$ computerized tomography (CT), magnetic resonance imaging (MRI), positron emission tomography (PET) and single photon emission tomography (SPECT) have no current role in the diagnostic evaluation of TS.

Tics can occur in other disorders besides TS, and specific diagnostic tests may be required to confirm these other disorders (see Table 2). Examples of these conditions include neuroacanthocytosis, Huntington's disease, Wilson's disease, Sydenham's chorea, head trauma, effects of certain drugs, and developmental disorders. ${ }^{17,23}$

Pediatric autoimmune neuropsychiatric disorders associated with streptococcal infections (PANDAS) is a more recently proposed postinfectious, immune-mediated form of TS and OCD. As in Sydenham's chorea, some investigators suggest that tics and obsessive-compulsive symptoms follow Group A $\beta$-hemolytic streptococcal infection. Current criteria for PANDAS include presence of tic disorder or OCD, onset of tics before puberty, episodic course of tics and obsessive-compulsive symptoms, documented evidence of a recent streptococcal infection, and temporal association between symptom exacerbation and streptococcal pharyngitis. ${ }^{24,25}$ Elevated anti-streptococcal antibody and anti-DNase B titers are not formally part of the definition and are not sufficient evidence to initiate antibiotic treatment.

Support for the PANDAS concept is mixed. Higher levels of serum antineuronal antibodies ${ }^{26-28}$ have been observed in TS samples compared with controls. Several labs have induced tic-like movements in laboratory ani- mals after brain infusion of sera from TS patients with high levels of autoantibodies, ${ }^{28-32}$ but this finding was not replicated in another study. ${ }^{33}$ In addition, a placebocontrolled study failed to show the effectiveness of prophylactic penicillin in preventing exacerbations of tic and obsessive-compulsive symptoms. ${ }^{34}$ Plasma exchange, in which offending autoantibodies are presumably removed, was effective in one study in children with TS and OCD, but it has not been replicated. ${ }^{35}$ Thus, although intriguing, the clinical implications of the autoimmune hypothesis are not yet clear. Throat cultures may be considered in patients with acute onset or exacerbations of TS symptoms or in patients complaining of pharyngitis. Treatment with antibiotics should not be initiated without clinical evidence of infection and a positive throat culture. Experimental treatments based on the autoimmune theory, such as plasma exchange, immunoglobulin therapy, or prophylactic antibiotic treatment, should not be undertaken outside of formal clinical trials.

\section{Evaluation and diagnosis of OCD, ADHD, and learning disability}

OCD. Obsessive-compulsive disorder is defined by the presence of recurrent, unwanted worries, thoughts, images, or impulses that are difficult to dislodge and/or the presence of repetitive behavior that the person feels compelled to perform. The diagnosis is appropriate when the patient or a close family reports that the obsessions or compulsions involve an average of an hour per day and interfere with daily living to some degree. In most cases, patients agree that the obsessive worries are greater than necessary and that the repetitive habits are excessive, but this awareness may not be present in younger children.

Several quantitative ratings are available for assessment of OCD in patients with TS, including clinician ratings, self-reports, and parent reports. The most commonly used clinician rating is the Yale-Brown Obsessive-Compulsive Scales (YBOCS) ${ }^{36,37}$ for adults and the companion (CYBOCS) for children and adolescents. ${ }^{13}$ Among the commonly used self-reports for obsessivecompulsive symptoms, only the Leyton Obsessional Inventory $^{38-40}$ has population- and clinic-based data supporting its reliability and validity. Detailed self-report versions of the YBOCS have also been introduced for evaluating the presence and severity of obsessive-compulsive symptoms. ${ }^{41}$

ADHD. Attention-deficit hyperactivity disorder is characterized by the early childhood onset of an enduring pattern of inattention and/or hyperactivity and impulsive behavior. ${ }^{16}$ Diagnosis and assessment of ADHD symptom severity in children and adolescents requires information from multiple informants including parents, teachers, and the child. This includes attention to the impact of the child's behavior on family members, peers, 
and school achievement. Clinic observation of the child's activity level, discourse, and ability to maintain focus is also essential; however, some children are able to restrain their behavioral expressions of ADHD during a clinic visit. Thus, the use of parent and teacher rating scales is the most practical way to collect information about the child's behavior across different settings (home and school). Examples of parent and teacher rating scales that have demonstrated reliability and validity for assessing ADHD and measurement of change with treatment include the Parent and Teacher Questionnaires developed by Conners ${ }^{42}$; the ADHD Rating Scales ${ }^{43}$; and the SNAP-IV. ${ }^{44}$ These measures can also be used to measure change with treatment. For example, the SNAP-IV was used as the primary outcome measure in a large multisite treatment trial in children with ADHD. ${ }^{45}$

One of the limitations of these ADHD rating scales is that the scores may be influenced by the parental reading ability or cultural background. A source of measurement error from teachers occurs when the rating of inattention and hyperactivity is confounded by the presence of behavioral problems. Consequently, these scales are useful in the clinical evaluation of ADHD in children with TS, but they should not be used as the only means of making the diagnosis. As with TS, the diagnosis of ADHD relies primarily on history.

Learning disability. Children and adolescents with TS who are failing academically should be considered for psychoeducational testing-especially if the child also has ADHD. ${ }^{46,47}$ A carefully conducted psychoeducational assessment can document the presence of a learning disability or more fine-grained difficulties with planning, organization, visual motor integration, and even impulse control. Importantly, even in the absence of a documented learning disability, the presence of tics, obsessive-compulsive symptoms, or ADHD may interfere with academic progress. If these symptoms do interfere with academic progress, the presence of TS can qualify a student for special educational assistance under current legislation addressing educational benefits for handicapped citizens.

\section{PHARMACOTHERAPY}

\section{General considerations}

The decision to use pharmacotherapy in TS begins with identification of target symptoms, which typically fall into one of three categories: tics, attention-deficit hyperactivity disorder, or obsessive-compulsive symptoms. This section describes the current evidence for medication treatment for each of these symptom domains. To guide clinical practice, the medications used in TS are classified according to their level of empirical support. The following criteria from the International Psychopharmacology Algorithm Project were selected:
Category A reflects treatments with Good supportive evidence for short-term safety and efficacy derived from at least two randomized placebo-controlled trials with positive results; Category B corresponds to treatments with Fair supportive data as evidenced by at least one positive placebo-controlled study; and Category $\mathrm{C}$ reflects treatments with Minimal supportive evidence such as open-label studies and accumulated clinical experience. $^{48}$

\section{TIC SYMPTOMS}

\section{Antipsychotics}

Traditional antipsychotics. The mainstay of treatment for tics has been the potent dopamine (D2) postsynaptic blockers. Several placebo-controlled trials have established the efficacy of the traditional antipsychotics, haloperidol and pimozide, for the treatment of tics. ${ }^{49-51}$ Randomized clinical trials comparing pimozide to haloperidol favored haloperidol in one study ${ }^{51}$ but showed equal efficacy in another. ${ }^{52}$ This study also showed that pimozide was better tolerated at equivalent doses. The dosages used in these studies ranged from 2 to $20 \mathrm{mg}$ per day for haloperidol and from 2 to $48 \mathrm{mg}$ /day for pimozide, with more recent studies at the low end of the range. In contemporary clinical practice, the trend is clearly toward the use of lower doses such as 1-4 $\mathrm{mg}$ for haloperidol and $2-8 \mathrm{mg}$ for pimozide ${ }^{53-55}$ Fluphenazine is another traditional antipsychotic of the phenothiazine class that is used in clinical practice, though it has not been well studied. A small controlled study of haloperidol, fluphenazine, and trifluoperazine found similar benefit for tics. Haloperidol was associated with more sedation and extrapyramidal side effects; fluphenazine was the best tolerated. ${ }^{56}$ At doses ranging from 2 to $15 \mathrm{mg} /$ day in two divided doses, fluphenazine was also effective in 17 of 21 patients in an open-label study that included both children and adults. ${ }^{57}$ In a naturalistic follow-up of 41 patients treated for at least 1 year, fluphenazine was reported to be safe and effective without a single occurrence of tardive dyskinesia. ${ }^{58}$

Atypical antipsychotics. The atypical antipsychotics include the more selective D2-blocking drugs (tiapride and sulpiride); drugs with serotonin-blocking effects but variable D2-blocking properties such as risperidone, olanzapine, ziprasidone, quetiapine, and clozapine; and the partial agonists such as aripiprazole. The differences in efficacy of the atypical antipsychotics for the treatment of tics appear to be related to the relative potency of dopamine blockade. For example, clozapine, which is a weak D2 blocker, does not appear to be effective for the treatment of tics. ${ }^{59}$ Since the introduction of the newer atypical antipsychotics, there has been increased interest in them as alternatives to the traditional medications in this class. After promising results from initial 
TABLE 3. Antipsychotic Drugs Used in the Treatment of Tics: Empirical Support and Dosing Guidelines

\begin{tabular}{lccc}
\hline Medication & $\begin{array}{c}\text { Empirical } \\
\text { Support }\end{array}$ & $\begin{array}{c}\text { Starting } \\
\text { Dose (mg) }\end{array}$ & $\begin{array}{c}\text { Usual Dose } \\
\text { Range (mg/day) }\end{array}$ \\
\hline Haloperidol & $\mathrm{A}$ & $0.25-0.5$ & $1-4$ \\
Pimozide & $\mathrm{A}$ & $0.5-1.0$ & $2-8$ \\
Risperidone & $\mathrm{A}$ & $0.25-0.5$ & $1.0-3.0$ \\
Fluphenazine & $\mathrm{B}$ & $0.5-1.0$ & $1.5-10$ \\
Tiapride & $\mathrm{B}$ & $50-150$ & $150-500$ \\
Ziprasidone & $\mathrm{B}$ & $10-20$ & $20-100$ \\
Olanzapine & $\mathrm{C}$ & $2.5-5.0$ & $2.5-12.5$ \\
Sulpiride & $\mathrm{C}$ & $100-200$ & $200-1000$ \\
Quetiapine & $\mathrm{C}$ & $25-50$ & $75-150$ \\
Aripiprazole & $\mathrm{C}$ & $2.5-5$ & $10-20$ \\
\hline
\end{tabular}

open-label reports, risperidone has been shown to be superior to placebo for tic reduction in two trials $s^{60,61}$ and equally effective to pimozide ${ }^{62,63}$ and clonidine. ${ }^{64}$ Two open-label trials of olanzapine in a total of 30 adult patients have shown encouraging results for the treatment of tics. ${ }^{65,66}$ The atypical antipsychotic ziprasidone has been evaluated in a pilot placebo-controlled study in 28 children with TS and was found to be superior to placebo in reducing tics. ${ }^{67}$ To date, only case reports are available for quetiapine ${ }^{68}$ and aripiprazole. ${ }^{69}$

The specific D2 receptor-blocking agents, tiapride and sulpiride, are commonly used for the treatment of tics in Europe, but they are not available in the United States. $^{70,71}$ In doses ranging from 5 to $6 \mathrm{mg} / \mathrm{kg}$ body wt/day, tiapride was superior to placebo in decreasing tics after 6 weeks of treatment in 27 children with TS. ${ }^{70}$ A retrospective study of sulpiride in 63 patients with TS (age 10 to 68 years) reported a positive response in more than $50 \%$ of the sample. ${ }^{71}$ Because several patients were also receiving other medications for tics, it is difficult to assess the benefits of sulpiride on tics. Table 3 summarizes the evidence-based category for each antipsychotic medication used in the treatment of tics as well as the typical starting and maintenance dose.

Adverse effects with the antipsychotics. The traditional antipsychotic drugs are associated with a range of possible neurological side effects, including parkinsonism, dystonia, dyskinesia, and akathisia in the short-term and tardive dyskinesia in the long-term. Other side effects may include cognitive blunting, depression, weight gain, and school phobia. ${ }^{72}$ The newer antipsychotics appear to have a lower percentage of neurological side effects in the short term. The relative risk of tardive dyskinesia is presumably lower, but more person-years of exposure to the atypical antipsychotics is required to confirm this speculation. Social phobia was observed in 2 of 12 risperidone-treated children with TS in the placebo-controlled study by Scahill and colleagues. ${ }^{61}$

An emerging concern with the atypical antipsychotics across several clinical populations is weight gain and related metabolic abnormalities. ${ }^{73-75}$ Based on reports from non-TS clinical populations, clozapine appears to associated with the highest risk of weight gain followed in order by olanzapine, quetiapine, risperidone, and ziprasidone. ${ }^{73}$ Another clinical consideration is the potential for some psychotropic drugs to prolong cardiac conduction times-especially prolonged QTc. Among currently available antipsychotics used in the treatment of tics, pimozide appears to be mostly likely to induce a prolonged QTc, although the occurrence is presumed to be rare in the dose ranges used in the treatment of tics. Nonetheless, a cardiogram is recommended before starting treatment with pimozide, during the dose-adjustment phase, and annually during ongoing treatment. ${ }^{53,55,76}$ Furthermore, because the risk for cardiac conduction abnormalities may increase when pimozide is combined with drugs that inhibit cytochrome P450 3A4 isoenzyme (e.g., clarithromycin) ${ }^{77}$ patients and families should be informed to check with treating clinicians before beginning a concomitant medication.

The association of prolonged QTc and risperidone, quetiapine, or olanzapine appears to be lower than pimozide. ${ }^{78}$ Approval of ziprasidone by the federal Food and Drug Administration (FDA) was delayed due to the Agency's concerns about QTc prolongation. Detailed examination of the cardiac effects of ziprasidone persuaded the FDA to approve the drug without specific warning about cardiac arrhythmia or recommendations for electrocardiogram monitoring. ${ }^{79}$ Furthermore, unlike pimozide, ziprasidone is not vulnerable to drug-drug interaction, as it uses more than one metabolic pathway. There are limited data on the use of ziprasidone in pediatric populations. One small study in 20 children with various psychiatric conditions showed a modest rise in QTc during treatment with ziprasidone. ${ }^{80}$ Until more data are available to inform practice, guidelines similar to those suggested for pimozide could be applied.

Nonantipsychotic medications. Several nonantipsychotic medications have been tried for the treatment of tics, though most have not been carefully studied (see Table 4). Clonidine is an $\alpha$-adrenergic agonist, antihypertensive agent that has been used in the treatment of TS for over 20 years. ${ }^{81}$ Despite its frequent use, controlled studies with clonidine are few in number. Side effects include sedation, dry mouth, headache, irritability, and midsleep awakening. Blood pressure and pulse should be measured at baseline and monitored during dose adjustment. Specific guidelines for blood pressure monitoring during follow up have not been established. Baseline and follow-up electrocardiograms have been recommended in some practice guidelines, ${ }^{82}$ but not others. ${ }^{83}$ Although blood pressure is generally not a problem with clonidine, patients and families should be educated about the potential for rebound increases in blood pressure, tics, and anxiety with abrupt discontinuation. ${ }^{84}$ 
TABLE 4. Nonantipsychotic Drugs Used in the Treatment of Tics: Empirical Support and Dosing Guidelines

\begin{tabular}{lccc}
\hline \multicolumn{1}{c}{ Medication } & $\begin{array}{c}\text { Empirical } \\
\text { Support }\end{array}$ & $\begin{array}{c}\text { Starting } \\
\text { Dose }(\mathrm{mg})^{*}\end{array}$ & $\begin{array}{c}\text { Usual Dose } \\
\text { Range } \\
\text { (mg/day)* }\end{array}$ \\
\hline Clonidine & $\mathrm{B}$ & $0.025-0.05$ & $0.10-0.30$ \\
Guanfacine & $\mathrm{B}$ & $0.5-1.0$ & $1.0-3.0$ \\
Pergolide & $\mathrm{B}$ & 0.025 & $0.10-0.4$ \\
Botulinum toxin & $\mathrm{B}$ & $30-300$ units in one or \\
Tetrabenazine & $\mathrm{C}$ & 25 & $37.5-150$ \\
Baclofen & $\mathrm{C}$ & 10 & $40-60$ \\
Nicotine Patch & $\mathrm{C}$ & 7 & $7-21$ \\
Mecamylamine & $\mathrm{C}$ & 2.5 & $2.5-7.5$ \\
Flutamide & $\mathrm{C}$ & 250 & $750^{\ddagger}$ \\
\hline
\end{tabular}

* Doses in mg unless otherwise specified.

${ }^{\dagger}$ Second controlled study was superior to placebo only when ticrelated impairment was included in the analysis.

¥Only one controlled study, superior to placebo, but magnitude of effect was small.

Guanfacine is another $\alpha$-adrenergic antihypertensive that has entered into clinical practice. To date there are two placebo-controlled trials of guanfacine in TS populations. ${ }^{85,86}$ In these trials, the tic severity of the study subjects was generally mild. Nonetheless, guanfacine was associated with a $30 \%$ decrease in tics from baseline in both studies. This level of improvement was significantly better than placebo in one study. ${ }^{85}$ Perhaps due to the small sample size, however, guanfacine was not superior to placebo in the other study. ${ }^{86}$ Whether guanfacine would be effective for the treatment of moderate to severe tics remains unanswered.

Two small controlled studies have evaluated the efficacy of fluoxetine for tics. ${ }^{87,88}$ Both studies found little or no benefit on tic symptoms. Tetrabenazine is a dopamine-depleting drug that acts by inhibiting central vesicular monoamine transporter type 2 (VMAT2). It is not on the market in the United States, and only two openlabel studies have been published. ${ }^{89,90}$ Taken together, these two studies treated 64 patients with TS. Of these, approximately two-thirds $(n=44)$ showed a moderate to marked reduction in tics on a clinician-rated global severity measure. Side effects included drowsiness, parkinsonism, depressed mood, insomnia, akathisia, and a few reports of dystonia.

Pergolide is a mixed dopamine agonist with action at both D1 and D2 receptors that is used to enhance dopamine function in Parkinson's disease. Given the putative heightened dopaminergic tone in TS, pergolide is hypothesized to turn off presynaptic synthesis of dopamine and bring about an improvement in tics. In the first open-label study, 24 of 32 subjects reportedly had a positive response. ${ }^{91}$ Two double-blind, placebo-controlled studies with pergolide showed superiority to pla- cebo. ${ }^{92,93}$ Interpreting the results of these studies is hindered by the confounding effects of the crossover design in the first study and equivocal benefits on tics in the second study. In the crossover study, the observed benefit between active and placebo was dramatically different in the first and second arm of the study. In the second study, which used a parallel design, pergolide was no better than placebo on the clinician-rated measure of tic severity. Superiority to placebo was demonstrated only when tic-related impairment was included in the analysis. Case reports of ergot-induced pleural, retroperitoneal, or pericardial fibrosis; vasospasm; and cardiotoxicity may limit the use of pergolide in Parkinson's disease and TS. There are no data on nonergoline dopamine agonists such as pramipexole and ropinirole. Finally, a placebo-controlled study with the partial dopamine agonist, talipexole, showed no positive effect on tics and several subjects complained of dizziness and nausea. ${ }^{94}$

Injection of botulinum toxin, which is a standard treatment for dystonia, has been evaluated in three open studies and one placebo-controlled trial in TS. ${ }^{95-97}$ The placebo-controlled study showed roughly a $40 \%$ difference between active drug and placebo. ${ }^{98}$ Botulinum toxin is injected directly into the selected muscle group involved in the motor tic or laryngeal folds in the case of vocal tic. ${ }^{99}$ The frequency of repeat injection has not been standardized, with a range of every 3 to 9 months across studies. Benefit is generally limited to the anatomical area of the injection. In open-label studies, the presence of premonitory urges predicted a higher likelihood of positive response. ${ }^{96,97}$ The botulinum toxin injections may in fact reduce the premonitory sensations at the injection site. ${ }^{98}$ Adverse effects include transient soreness at the injection site, weakness of the injected muscle, and loss of voice volume if the vocal cords are the target of treatment.

Drugs affecting brain GABA systems have been of interest as possible treatments for TS. Although there are no placebo-controlled trials in TS, open-label studies of the long-acting benzodiazepine, clonazepam, have been carried out in adults ${ }^{100}$ and adolescents with TS. ${ }^{101}$ At doses ranging from 0.5 to $4 \mathrm{mg} /$ day given in two or three divided doses, clonazepam showed only modest benefits. Side effects include sedation, short-term memory problems, ataxia, and disinhibition. These adverse events, especially disinhibition, often limit the use of clonazepam in children. ${ }^{102}$

Baclofen, which is a GABA ${ }_{B}$ receptor agonist used for the treatment of spasticity, has been examined in an open-label study and one small placebo-controlled study. ${ }^{103}$ The results of these studies provide only modest support for the use of baclofen in TS. Other GABAergic drugs include the anticonvulsants topiramate and levetiracetam. Although the mechanisms of action are quite different, topiramate and levetiracetam have been 
TABLE 5. Percent Improvement for Medications Showing Superiority to Placebo for the Treatment of Tics

\begin{tabular}{lc}
\hline \multicolumn{1}{c}{ Drug } & Improvement* $(\%)$ \\
\hline Clonidine & 35 \\
Guanfacine & $30-37$ \\
Pergolide & 35 \\
Botulinum toxin & 40 \\
Ziprasidone & 35 \\
Risperidone & $35-50$ \\
Haloperidol & 66 \\
Pimozide & $39-58$ \\
Tiapride & 44 \\
\hline
\end{tabular}

* Without adjustment for placebo.

examined in open studies in TS. ${ }^{104,105}$ Initial results in open-label studies are encouraging. For example, Awaad and colleagues ${ }^{105}$ conducted an open study with levetiracetam in 60 children with TS. At doses ranging from 1000 to $2000 \mathrm{mg} /$ day, they observed an average $20 \%$ decrease in tics. Enthusiasm for topiramate has diminished due to reports of acute angle-closure glaucoma. ${ }^{106}$

Nicotine, administered as a transdermal patch or chewing gum, has been evaluated in open-label studies and one controlled study. These studies provide unconvincing evidence that nicotine can provide an adjunctive benefit for tic suppression when added to ongoing treatment with an antipsychotic. ${ }^{107-109}$ Mecamylamine, a nicotinic receptor antagonist, was no better than placebo in reducing tics. ${ }^{10,111}$ The antiandrogen flutamide, which has theoretical appeal for the treatment of tics, showed little clinical benefit in the only placebo-controlled study. ${ }^{112}$

\section{Pharmacotherapy for tics: conclusion}

Table 5 compares the percent improvement in tics from drugs evaluated in placebo-controlled trials. At first glance, haloperidol appears to be the most effective for reducing tics. However, due to the side effect burden of haloperidol, many clinicians avoid it as a first line for the treatment of tics. In cases with mild tics, tic-suppressing medication may not be indicated. For tics of moderate or greater severity, guanfacine or clonidine may be considered as the first line given the favorable safety margin of these medications. In patients with moderate tics, the $30 \%$ decrease in tic severity associated with guanfacine or clonidine may be sufficient. Botulinum toxin may be considered in patients with single, interfering tic. However, treatment guidelines on dose and frequency of injection remain somewhat uncertain. For tics in the marked or severe range, however, more potent medications such as risperidone, pimozide, ziprasidone, or fluphenazine should be considered.

\section{Treatment of obsessive-compulsive disorder}

The tricyclic antidepressant, clomipramine, was the first effective drug treatment for OCD. Early studies showed that clompramine was more effective in OCD than its close chemical relative, desipramine. ${ }^{113}$ Unlike desipramine, which is a selective norepinephrine reuptake blocker, clomipramine also has serotonin reuptake blocking properties. Clomipramine has been studied in both adult and pediatric populations and has demonstrated superiority to placebo in several controlled trials. ${ }^{114,115}$ These observations led to the evaluation of more selective serotonin reuptake inhibitors (SSRIs). Currently, there are six SSRIs on the market: fluoxetine, fluvoxamine, sertraline, paroxetine, citalopram, and escitalopram. All but escitalopram has demonstrated efficacy in the treatment of OCD in adults (see ${ }^{116}$ and ${ }^{117}$ for reviews). ${ }^{118}$ Of these, all but citalopram and escitaolpram have also been evaluated in controlled studies in pediatric populations. ${ }^{119-124}$ The POTS study is the only trial to examine the combined use of medication and cognitive-behavioral therapy (CBT) based on exposure and response prevention in a pediatric sample. In that study, the combined treatment was more effective than either CBT alone or sertraline alone.

Table 6 shows the level of empirical support and typical dose range for clomipramine and the SSRIs in children and adults. A guiding principle in using these medications in pediatric populations is to start with low doses and increase gradually. This is especially true of fluoxetine and citalopram, which have relatively long halflives. The side effects of the SSRIs include headache, sedation, insomnia, behavioral activation, akathisia, nausea, vomiting, diarrhea, anorexia, and sexual dysfunction. Children may be at a higher risk for activation than adults. ${ }^{125}$ If these side effects do not subside with continued treatment, the dosage should be reduced. In some cases, the level of activation is unacceptable and discontinuation is required.

Another issue that has emerged with the SSRIs, particularly when used in children and adolescents, is the concern about suicidal ideation and behavior. ${ }^{126} \mathrm{Al}$ though this is not a new issue, ${ }^{127}$ it has become a matter

TABLE 6. Medications Used in the Treatment of $O C D$ : Empirical Support and Dosing Guidelines

\begin{tabular}{|c|c|c|c|c|}
\hline \multirow[b]{2}{*}{ Medication } & \multicolumn{2}{|c|}{$\begin{array}{l}\text { Empirical } \\
\text { Support }\end{array}$} & \multirow{2}{*}{$\begin{array}{c}\text { Starting } \\
\text { Dose }(\mathrm{mg})\end{array}$} & \multirow{2}{*}{$\begin{array}{c}\text { Usual Dose } \\
\text { Range (mg/day) }\end{array}$} \\
\hline & Child & Adult & & \\
\hline Clomipramine & $\mathrm{A}$ & A & $25-50$ & $100-250$ \\
\hline Fluoxetine & A & A & $5-20$ & $10-60$ \\
\hline Sertraline & A & A & $25-50$ & $50-250$ \\
\hline Fluvoxamine & A & A & $25-50$ & $50-350$ \\
\hline Paroxetine & B & A & $5-10$ & $10-60$ \\
\hline Citalopram & B & A & $5-10$ & $20-60$ \\
\hline Escitalopram* & B & A & $5-10$ & $10-20$ \\
\hline
\end{tabular}

* Not well studied in OCD, presumed to be similar in efficacy to citalopram. 
of increased concern after the release of data from several pediatric depression studies in Britain. In these placebo-controlled studies of children and adolescents with major depression, youngsters treated with paroxetine reported a higher frequency of self-injurious thoughts and behavior than the placebo group. Given that these patients were being treated for depression, it is not clear whether these findings apply to children with OCD that are treated with SSRIs.

The clinical management of patients treated with an SSRI or clomipramine also warrants attention to the potential for drug-drug interaction. For example, erythromycin, which potently inhibits the CYP 3A4 isoenzyme, can raise the level of clomipramine to toxic levels. ${ }^{128}$ Common drugs such as cimetadine may inhibit the activity of several CYP isoenzymes resulting in an increased level of the antiobsessional medication. The SSRIs can also inhibit the action of these hepatic enzyme systems, which could have a clinically significant impact on the levels of the other drugs. Fluoxetine and paroxetine are potent inhibitors of 2D6, which is a common pathway for several drugs, including risperidone and haloperidol. Thus, the addition of fluoxetine or paroxetine to ongoing treatment with risperidone or haloperidol will raise the level of the antipsychotic and increase the likelihood of adverse effects. Fluvoxamine is an inhibitor of $3 \mathrm{~A} 4$, which will predictably raise the level of pimozide or clomipramine.

Special consideration is warranted when discontinuing the shorter acting SSRIs: sertraline, fluvoxamine, and paroxetine. Several case reports and one prospective study have shown that abrupt discontinuation of these medications is associated with a withdrawal syndrome characterized by flu-like symptoms and depressed mood. ${ }^{129}$

It has been estimated that 30 to $40 \%$ of OCD patients will show only partial or no response to one or more adequate trials of clomipramine or an SSRI. This observation has led to various combination medication strategies (see ${ }^{130}$ for a review and Combined Therapy).

\section{Pharmacotherapy for OCD: conclusion}

Based on available evidence, there is no compelling evidence to support the selection of any one SSRI or clomipramine as the first line treatment. Fluoxetine, sertraline, and fluvoxamine appear to be equal in efficacy and each has been studied in pediatric samples for disorders other than OCD. Citalopram and paroxetine have each been shown to be effective in adults with OCD and have some supportive evidence for the treatment of children with OCD as well. The combined use of CBT (especially exposure and response prevention) with medication is likely to produce better and more enduring therapeutic results. ${ }^{124}$
As with the other tricyclics, clomipramine can cause a prolongation of the QT interval. ${ }^{131}$ Clomipramine is also associated with a range of other side effects, such as tachycardia, fatigue, dizziness, dry mouth, sweating, tremor, constipation, urinary retention, and weight gain. Thus, clomipramine is generally not the drug of first choice for OCD. On the other hand, in light of its pharmacological differences from the SSRIs, it should be considered when a patient has failed two SSRI trials. ${ }^{132}$ Case reports suggest that intravenous administration of clomipramine may be useful in refractory OCD. ${ }^{133-135}$

\section{Treatment of ADHD}

The stimulants are the first line agents for the treatment of ADHD. ${ }^{45,136}$ Stimulants fail in 10 to $20 \%$ of ADHD cases $^{137}$ either because of lack of efficacy or adverse effects, including tics. ${ }^{138-143}$ The emergence of tics in some children with ADHD has also been documented in two placebo-controlled trials that excluded subjects with tic disorders. ${ }^{144,145}$ The results of these studies indicate that stimulants may induce tics in some children without pre-existing tics and lead to discontinuation.

In contrast to these clinical observations, three placebo-controlled studies have evaluated the short-term effects of stimulants on children with ADHD and tic disorders. ${ }^{146-148}$ Two naturalistic studies have examined the long-term effects of stimulants in TS. ${ }^{149,150}$ The findings of these studies suggest that children with ADHD and tics do not invariably manifest an increase in tics upon exposure to stimulant medication, though an exacerbation in tics may occur in some cases.

Drugs from several classes have been used as alternatives to the stimulants in children or adults with ADHD. These include the $\alpha-2$ agonists, clonidine and guanfacine; the tricyclic antidepressants, desipramine and nortriptyline; the newer antidepressants, bupropion, venlafaxine, and atomoxetine; the beta blocker, pindolol; and the selective monoamine oxidase inhibitor, deprenyl. Table 7 shows the level of empirical support for these medications in the treatment of ADHD.

Despite the positive results of three placebo-controlled studies, ${ }^{151-153}$ many clinicians are reluctant to use desipramine because of concerns about prolonged cardiac conduction times. ${ }^{131,154}$ Nortriptyline, also a tricyclic, has been less well studied in ADHD. In doses ranging from 50 to $200 \mathrm{mg}$ /day given in divided doses, bupropion was generally well tolerated and equal to methylphenidate in one study ${ }^{155}$ and superior to placebo. ${ }^{156-158}$ Case reports have suggested that bupropion may accentuate tic symptoms. ${ }^{159}$ Although presumably rare, bupropion may increase the risk of seizures in vulnerable individuals. ${ }^{160}$

The beta blocker, pindolol, was evaluated in one controlled study that compared it to placebo and methylphenidate. At a dose of $20 \mathrm{mg}$ twice daily, pindolol effectively reduced ADHD symptoms, but two subjects 
TABLE 7. Nonstimulants Used in the Treatment of ADHD: Empirical Support and Dosing Guidelines

\begin{tabular}{lccc}
\hline Medication & $\begin{array}{c}\text { Empirical } \\
\text { Support }\end{array}$ & $\begin{array}{c}\text { Starting } \\
\text { Dose (mg) }\end{array}$ & $\begin{array}{c}\text { Usual Dose } \\
\text { Range (mg/day) }\end{array}$ \\
\hline Desipramine & $\mathrm{A}$ & $10-25$ & $50-150$ \\
Nortriptyline & $\mathrm{C}$ & $10-25$ & $20-100$ \\
Clonidine & $\mathrm{B}$ & $0.025-0.05$ & $0.15-0.3$ \\
Guanfacine & $\mathrm{B}$ & $0.25-0.5$ & $1.5-3.5$ \\
Bupropion & $\mathrm{A}$ & $25-50$ & $75-150$ \\
Deprenyl & $\mathrm{B}$ & 5.0 & $5-15$ \\
Venlafaxine & $\mathrm{B} *$ & 37.5 & $75-200$ \\
Atomoxetine & $\mathrm{A}$ & $10-20$ & $40-80$ \\
Pindolol & $\mathrm{B}$ & $5-10$ & $15-40$ \\
\hline
\end{tabular}

* Data in pediatric populations are limited.

developed nightmares and hallucinations, raising questions about the usefulness of pindolol in ADHD at this dose level. ${ }^{161}$

Deprenyl, which is a selective monoamine oxidase inhibitor that enhances dopaminergic function, is used in the treatment of Parkinson's disease. One open-label study ${ }^{96}$ and one placebo-controlled crossover study ${ }^{162}$ suggest that deprenyl may be effective for the treatment of ADHD in children with TS without increasing tics. Clear interpretation of the results from the crossover study is hampered by the apparent order effect. At low doses (5-10 mg/day), deprenyl does not require dietary restrictions. However, data on drug interaction in nonParkinson populations are limited.

Although clonidine has been used for over 20 years in the treatment of TS, there are few placebo-controlled studies evaluating its effects on ADHD symptoms. ${ }^{81,163}$ In a crossover study of 34 subjects with ADHD and TS, Singer and colleagues ${ }^{152}$ compared clonidine to desipramine and placebo and found that clonidine was no better than placebo after 6 weeks of treatment. Connor and colleagues ${ }^{164}$ randomly assigned 24 subjects to receive clonidine only, clonidine plus methylphenidate or methylphenidate alone ( $n=8$ in each group) in an open-label study. All treatment groups showed improvement in ADHD symptoms after 3 months of treatment.

The Tourette Syndrome Study Group ${ }^{148}$ conducted a multisite, randomized trial with four groups including clonidine alone, methylphenidate alone, clonidine and methylphenidate, and placebo. The 136 subjects with a tic disorder and ADHD ranged from 7 to 14 years. The clonidine-alone group showed a $40 \%$ improvement on the primary teacher rating compared with $38 \%$ for the methylphenidate group and 59\% for combined treatment. The stimulant doses used were slightly less than most contemporary methylphenidate studies (e.g., ${ }^{45}$ ), which may explain the modest improvement observed in the methylphenidate-alone group. ${ }^{165}$ Approximately a quarter of the subjects in the clonidine and methylphenidate only groups showed an increase in tics, which was only slightly higher than the rate observed in the placebo group. In general, the tics improved across all treatment groups.

Guanfacine has been evaluated in three open-label studies and one randomized controlled trial in children and adolescents with ADHD. ${ }^{85,166-168}$ In the doubleblind study involving 34 youngsters with ADHD and a tic disorder, guanfacine was significantly better than placebo on teacher ratings of classroom behavior. ${ }^{85}$ At doses ranging from 1.5 to $4 \mathrm{mg}$ /day in three divided doses (in most cases), guanfacine was well tolerated across these four studies with mild, transient sedation being the most common adverse effect. Other adverse effects included constipation and midsleep awakening. As noted above, guanfacine was also evaluated in a second placebo-controlled study by Cummings and colleagues. ${ }^{86}$ This study did not select subjects with ADHD and baseline ratings varied widely from the normal to the pathological range. In addition, the Cummings et al. ${ }^{86}$ study included only 12 subjects per group. The heterogeneity in the sample and the small sample size make it difficult to interpret the findings of this study on ADHD symptoms.

\section{Pharmacotherapy of ADHD in children and adolescents with TS: Conclusion}

Observational data accumulated over three decades suggests that the stimulants may worsen tics in some children and adolescents with ADHD. Well-established animal models also support the view that stimulant exposure can induce stereotypic behavior. ${ }^{169}$ Nonetheless, several placebo-controlled trials have conclusively shown that stimulant-induced exacerbation of tics is not an inevitable outcome for children with TS and ADHD. Indeed, increased tics after stimulant exposure may only occur in a minority of cases with this combined syndrome. ${ }^{148}$ Given the added disability attributable to ADHD in children and adolescents with TS, ${ }^{170}$ aggressive treatment of ADHD in these cases is warranted. After a review of the alternatives and the family's preference, treatment may start with an $\alpha-2$ agonist (guanfacine or clondine) or stimulant medication. Combined treatment with an $\alpha-2$ agonist and stimulant may produce better outcomes than either treatment alone.

Atomoxetine is a selective norepinephrine reuptake inhibitor that has shown superiority to placebo in studies of children with ADHD not accompanied by tics. In contrast to desipramine, which is also a selective norepinephrine inhibitor, atomoxetine appears unlikely to induce cardiac arrhythmia. In a pair of double-blind, placebo-controlled studies involving 467 children with ADHD between the ages of 6 and 18 years, Michelson et $\mathrm{al}^{171,172}$ showed that atomoxetine at doses ranging from $1.3-1.8 \mathrm{mg} / \mathrm{kg}$ body $\mathrm{wt} /$ day were superior to placebo on a measure of ADHD symptoms. The group receiving 0.5 
$\mathrm{mg} / \mathrm{kg}$ dose, however, fared no better than placebo. ${ }^{171}$ The manufacturer suggests giving a single morning dose beginning with roughly $0.5 \mathrm{mg} / \mathrm{kg} /$ day followed by gradual increases to $1.0-1.5 \mathrm{mg} / \mathrm{kg} / \mathrm{day}$. However, to deal with adverse effects and maintain therapeutic benefit across the entire day, atomoxetine may be given in two divided doses. Common adverse effects with atomoxetine include nausea, vomiting, loss of appetite, and insomnia. Other nonstimulants including bupropion, pindolol, and deprenyl could be considered third-line treatments.

\section{Mood and anxiety disorders}

The high prevalence of OCD and ADHD in TS populations is well documented. Less well-documented, though commonly seen in clinical samples, are comorbid depression, bipolar disorder, generalized anxiety disorder, and separation anxiety. ${ }^{173-179}$ The high rates of these conditions may reflect spurious associations due to ascertainment bias, TS genetic pleiotropy, ${ }^{180}$ TS phenocopies ${ }^{181}$ or secondary problems caused by the burden of a chronic neuropsychiatric disorder. ${ }^{182}$

Despite the uncertainties concerning whether any or all of these comorbid conditions are etiologically related to TS, there is no evidence that TS patients with one or more of these conditions will respond differently than patients without TS. Thus, pharmacotherapy for comorbid bipolar disorder, depression, and anxiety should proceed according to current practice.

Several consensus documents for both adults and children have been published and should be consulted for a detailed review of practice guidelines. ${ }^{126,183-187}$

\section{Aggression and explosive behavior}

The frequency of aggression in patients with TS varies from 26 to $75 \%$ depending on the sample. ${ }^{170,188,189} \mathrm{~A}$ variety of medications, including anticonvulsants, lithium, propranolol, psychostimulants, clonidine, and antipsychotics, have been used clinically in TS patients, but there are no controlled studies. An open trial of paroxetine (average dose $33.3 \mathrm{mg} /$ day) in 45 patients with TS and explosive anger outbursts showed a significant decrease in both intensity and frequency of outbursts in $76 \%$ ( $n=34)$. Four subjects reported worsening of symptoms. ${ }^{190}$ The atypical antipsychotic medication, olanzapine, was examined in a pilot study of 10 youngsters with TS and showed positive effects. Aggression and explosive behavior have been evaluated in placebo-controlled trials in other clinical populations, including risperidone in children with autism ${ }^{191}$; risperidone in children with subaverage intelligence and disruptive behavior ${ }^{192}$; and valproate in adolescents with average intelligence and disruptive behavior. ${ }^{193}$ This is an area that warrants further study with both pharmacological and psychosocial interventions.

\section{Combined pharmacotherapy}

There are few reports of combined pharmacotherapies in TS patients. Nonetheless, the use of multiple medications is probably quite common in clinical practice as evidenced by several open-label reports ${ }^{71,149,189,194}$ and a controlled study in which fluoxetine was added to existing medication treatment in children with TS and obsessive-compulsive symptoms. ${ }^{87}$ The primary reasons that clinicians resort to combined pharmacotherapy are to enhance effectiveness of the first medication, ${ }^{148}$ to treat a comorbid condition (e.g., TS and ADHD), or to manage side effects of the first medication (use of clonidine for sleep problems in children with TS and ADHD).

Two controlled studies in adults with refractory OCD illustrate the use of combined therapy to enhance an incomplete response to monotherapy. The first study compared the addition of either haloperidol or placebo to a stable dose of a selective serotonin reuptake inhibitor (SSRI) in adults with refractory OCD. ${ }^{195}$ In that study, haloperidol was significantly better than placebo as an adjunct to an SSRI for OCD. Moreover, patients with a history of tics were more likely to benefit from the addition of this antipsychotic. A subsequent study by the same group evaluated the addition of risperidone compared with placebo in adults with refractory OCD. Risperidone was also effective as an adjunctive therapy, but a history of tics was not predictive of positive response. $^{196}$

The use of combined drug therapy is tempered by the lack of data and the potential for drug-drug interaction. As noted previously, inhibition of hepatic enzyme systems by SSRIs may have a dramatic effect on blood level of the other medication in use. As evidenced by case reports of adding fluvoxamine to clomipramine in a child with severe OCD, clinicians may try to exploit this interaction for clinical benefit, ${ }^{197}$ but this strategy has not been carefully studied. As noted previously, inhibition of hepatic metabolism has also been implicated in serious adverse events including death via cardiotoxic effects. ${ }^{77}$

In conclusion, the decision to use medication in TS follows careful assessment and identification of target symptoms that are interfering in the patient's quality of life. The selection of medication is based on available evidence and careful balance of the risks and benefits. For example, given the risks associated with antipsychotic medications, it would not be appropriate to use this class of medications in the treatment of mild tics. Selective serotonin reuptake inhibitors are first-line agents for obsessive-compulsive disorder, but the magnitude of response is typically modest. Given this modest response, antiobsessional medication is indicated when symptom severity is moderate or greater. The disability associated with ADHD mandates medication treatment regardless of tic severity. Medications are unlikely to eliminate all symptoms in the targeted area. Thus, clini- 
cians should remind patients and families that high levels of medication may tip the risk/benefit equation in the unfavorable direction.

Acknowledgments: We acknowledge the efforts Donald L. Gilbert, M.D. for review of this manuscript and Erin Kustan for her assistance in preparing this manuscript.

Portions of this manuscript were published by the Tourette Syndrome Association as a monograph by the TSA Practice Parameter Group.

\section{REFERENCES}

1. Jankovic J. Tourette's syndrome. N Engl J Med 345:1184-1192, 2001.

2. Leckman JF. Tourette's syndrome. Lancet 360:1577-1586, 2002.

3. Piacentini J, Chang S. Behavioral treatments for Tourette syndrome and tic disorders: state of the art. Adv Neurol 85:319-331, 2001.

4. Craighead WE, Craighead LW. The role of psychotherapy in treating psychiatric disorders. Med Clin North Am 85:617-629, 2001.

5. Foa EB, Franklin ME, Moser J. Context in the clinic: how well do cognitive-behavioral therapies and medications work in combination? Biol Psychiatry 52:987-997, 2002.

6. Wells KC, Pelham WE, Kotkin RA, Hoza B, Abikoff HB, Abramowitz A et al. Psychosocial treatment strategies in the MTA study: rationale, methods, and critical issues in design and implementation. J Abnorm Child Psychol 28:483-505, 2000.

7. Wilhelm S, Deckersbach T, Coffey BJ, Bohne A, Peterson AL, Baer L. Habit reversal versus supportive psychotherapy for Tourette's disorder: a randomized controlled trial. Am J Psychiatry 160:1175-1177, 2003.

8. Temel Y, Visser-Vandewalle V. Surgery in Tourette syndrome. Mov Disord 19:3-14, 2004.

9. Houeto JL, Karachi C, Mallet L, Pillon B, Yelnik J, Mesnage V et al. Tourette's syndrome and deep brain stimulation. J Neurol Neurosurg Psychiatry 76:992-995, 2005.

10. Goetz CG, Kompoliti K. Rating scales and quantitative assessment of tics. Adv Neurol 85:31-42, 2001.

11. Scahill L, King RA, Schultz RT, Leckman JF. Selection and use of diagnostic and clinician rating instruments. In: Tourette's syndrome: tics, obsessions, compulsions: developmental psychopathology and clinical care (Leckman JF, Cohen DJ, eds), pp 310324. New York: Wiley, 1999.

12. Leckman JF, Riddle MA, Hardin MT, Ort SI, Swartz KL, Stevenson J, et al. The Yale Global Tic Severity Scale: initial testing of a clinician-rated scale of tic severity. J Am Acad Child Adolesc Psychiatry 28:566-573, 1989.

13. Scahill L, Riddle M, McSwiggin-Hardin M, Ort SI, King RA, Goodman WK et al. Children's Yale-Brown Obsessive Compulsive Scale: reliability and validity. I Am Acad Child Adolesc Psychiatry 36:844-852, 1997.

14. Kwak C, Dat Vuong K, Jankovic J. Premonitory sensory phenomenon in Tourette's syndrome. Mov Disord 18:1530-1533, 2003.

15. The Tourette Syndrome Classification Group. Definitions and classifications of tic disorders. Arch Neurol 50:1013-1016, 1993.

16. American Psychiatric Association. Diagnostic and statistical manual, fourth edition: treatment revision. Washington, DC: American Psychiatric Association Press, 2000.

17. Jankovic J. Differential diagnosis and etiology of tics. Adv Neurol 85:15-29, 2001.

18. Rothenberger A, Kostanecka T, Kinkelbur J, Cohrs S, Woerner W, Hajak G. Sleep and Tourette syndrome. Adv Neurol 85:245259,2001

19. Kostanecka-Endress T, Banaschewski T, Kinkelbur J, Wullner I, Lichtblau S, Cohrs S et al. Disturbed sleep in children with Tourette syndrome: a polysomnographic study. J Psychosom Res 55:23-29, 2003.
20. Peterson, BS, Staib L, Scahill L, Zhang H, Anderson C, Leckman $\mathrm{JF}$ et al. Regional brain and ventricular volumes in Tourette syndrome. Arch Gen Psychiatry 58:427-440, 2001.

21. Singer HS, Szymanski S, Giuliano J, Yokoi F, Dogan AS, Brasic JR et al. Elevated intrasynaptic dopamine release in Tourette's syndrome measured by PET. Am J Psychiatry 159:1329-1336, 2002.

22. Peterson BS, Thomas P, Kane MJ, Scahill L, Zhang H, Bronen R et al. Basal ganglia volumes in patients with Gilles de la Tourette syndrome. Arch Gen Psychiatry 60:415-424, 2003.

23. Kumar R, Lang AE. Tourette syndrome: secondary tic disorders. Neurol Clin 15:309-331, 1997.

24. Murphy TK, Sajid M, Soto O, Shapira N, Edge P, Yang M. Detecting pediatric autoimmune neuropsychiatric disorders associated with streptococcus in children with obsessive-compulsive disorder and tics. Biol Psychiatry 55:61-68, 2004.

25. Swedo SE. Pediatric autoimmune neuropsychiatric disorders associated with streptococcal infections (PANDAS). Mol Psychiatry 7:S24-S25, 2002.

26. Hallett JJ, Kiessling LS. Neuroimmunology of tics and other childhood hyperkinesias. Neurol Clin 15:333-344, 1997.

27. Singer HS, Guiliano JD, Hansen BH, Hallett JJ, Laurino JP, Benson $\mathrm{M}$ et al. Antiobodies against human putamen in children with Tourette syndrome. Neurology 50:1618-1624, 1998.

28. Morshed SA, Parveen S, Leckman JF, Mercadante MT, Bittencourt Kiss MH, Miguel EC et al. Antibodies against neural, nuclear, cytoskeletal, and streptococcal epitopes in children and adults with Tourette's syndrome, Sydenham's chorea, and autoimmune disorders. Biol Psychiatry 50:566-577, 2001.

29. Loiselle CR, Wendlandt JT, Rohde CA, Singer HS. Antistreptococcal, neuronal, and nuclear antibodies in Tourette syndrome. Pediatr Neurol 28:119-125, 2003.

30. Hallett JJ, Harling-Berg CJ, Knopf PM, Stopa EG, Kiessling LS. Anti-striatal antibodies in Tourette syndrome cause neuronal dysfunction. J Neuroimmunol 111:195-202, 2000.

31. Taylor JR, Morshed SA, Parveen S, Mercadante MT, Scahill L, Peterson BS et al. An animal model of Tourette's syndrome. Am J Psychiatry 159:657-660, 2002.

32. Church AJ, Dale RC, Lees AJ, Giovannoni G, Robertson MM Tourette's syndrome: a cross sectional study to examine the PANDAS hypothesis. J Neurol Neurosurg Psychiatry 74:602-607, 2003.

33. Loiselle CR, Lee O, Moran TH, Singer HS. Striatal microinfusion of Tourette syndrome and PANDAS sera: failure to induce behavioral changes. Mov Disord 19:390-396, 2004.

34. Garvey MA, Perlmutter SJ, Allen AJ, Hamburger S, Lougee L, Leonard HL et al. A pilot study of penicillin prophylaxis for neuropsychiatric exacerbations triggered by streptococcal infections. Biol Psychiatry 45:1564-1571, 1999.

35. Perlmutter SJ, Leitman SF, Garvey MA, Hamburger S, Feldman E, Leonard HL et al. Therapeutic plasma exchange and intravenous immunoglobulin for obsessive-compulsive disorder and tic disorders in childhood. Lancet 354:1153-1158, 1999.

36. Goodman WK, Price LH, Rasmussen SA, Mazure C, Fleischmann RL, Hill CL et al. The Yale-Brown Obsessive Compulsive Scale. I. Development, use, and reliability. Arch Gen Psychiatry 46:1006-1011, 1989.

37. Goodman WK, Price LH, Rasmussen SA, Mazure C, Delgado P, Heninger GR et al. The Yale-Brown Obsessive Compulsive Scale. II. Validity. Arch Gen Psychiatry 46:1012-1016, 1989.

38. Cooper J. The Leyton obsessional inventory. Psychol Med 1:4864, 1970.

39. Berg CJ, Rapoport JL, Flament M. The Leyton obsessional inventory: child version. J Am Acad Child Adolesc Psychiatry 25:84-91, 1986.

40. Berg CZ, Whitaker A, Davies M, Flament MF, Rapoport JL. The survey form of the Leyton obsessional inventory: child version. Norms from an epidemiological study. J Am Acad Child Adolesc Psychiatry 27:759-763, 1988.

41. Leckman JF, Walker DE, Goodman WK, Pauls DL, Cohen DJ. "Just right" perceptions associated with compulsive behavior in Tourette's syndrome. Am J Psychiatry 151:675-680, 1994. 
42. Goyette $\mathrm{CH}$, Conners CK, Ulrich RF. Normative data on revised Conners Parent and Teacher Rating scales. J Abnorm Child Psychol 6:221-236, 1978.

43. DuPaul GJ, Power TJ, McGoey KE, Ikeda MJ, Anastopoulos AD. Reliability and validity of parent and teacher ratings of attentiondeficit/hyperactivity disorder symptoms. J Psychoeduc Assess 16: 55-68, 1998.

44. Swanson J, Lerner M, March J, Gresham FM. Assessment and intervention for attention-deficit/hyperactivity disorder in the schools: lessons from the MTA study. Pediatr Clin North Am 46:993-1009, 1999.

45. MTA Cooperative Group. Multimodal Treatment Study of Children with ADHD: a 14-month randomized clinical trial of treatment strategies for attention-deficit/hyperactivity disorder. Arch Gen Psychiatry 56:1073, 1999.

46. Schultz RT, Carter AS, Gladstone M, Scahill L, Leckman JF, Peterson BS et al. Visual-motor integration functioning in children with Tourette syndrome. Neuropsychology 12:134-145, 1998.

47. Como PG. Neuropsychological function in Tourette syndrome. Adv Neurol 85:103-111, 2001.

48. Jobson KO, Potter WZ. International Psychopharmacology Algorithim Project Report: introduction. Psychopharmacol Bull 31: 457-459, 1995.

49. Ross MS, Moldofsky H. A comparison of pimozide and haloperidol in the treatment of Gilles de la Tourette syndrome. Am J Psychiatry 135:585-587, 1978.

50. Shapiro AK, Shapiro E. Controlled study of pimozide vs placebo in Tourette's syndrome. J Am Acad Child Adolesc Psychiatry 23:161-173, 1984.

51. Shapiro E, Shapiro AK, Fulop G, Hubbard M, Mandell J, Nordlie $\mathrm{J}$ et al. Controlled study of haloperidol, pimozide, and placebo for the treatment of Gilles de la Tourette's syndrome. Arch Gen Psychiatry 46:722-730, 1989.

52. Sallee FR, Nesbitt L, Jackson C, Sine L, Sethuraman G. Relative efficacy of haloperidol and pimozide in children and adolescents with Tourette's disorder. Am J Psychiatry 154:1057-1062, 1997.

53. Kurlan R. Treatment of tics. Neurol Clin North Am 15:403-409, 1997.

54. Riddle MA, Carlson J. Clinical psychopharmacology for Tourette syndrome and associated disorders. Adv Neurol 85:343-354, 2001.

55. Scahill L, Chappell PB, King RA, Leckman JF. Pharmacological treatment of tic disorders. Child Adolesc Psychiatr Clin North Am 9:99-117, 2000.

56. Borison RL, Ang L, Chang S, Dysken M, Comaty JE, Davis JM. New pharmacological approaches in the treatment of Tourette syndrome. Adv Neurol 35:377-382, 1982.

57. Goetz CG, Tanner CM, Klawans HL. Fluphenazine and multifocal tic disorders. Arch Neurol 41:271-272, 1984.

58. Silay YS, Vuong KD, Jankovic J. The efficacy and safety of fluphenazine in patients with tourette syndrome. Neurology 62: A506, 2004.

59. Caine ED, Polinsky RJ, Kartzinel R, Ebert MH. The trial use of clozapine for abnormal involuntary disorders. Am J Psychiatry 136:317-320, 1979.

60. Dion Y, Annable L, Sandor P, Chouinard G. Risperidone in the treatment of tourette syndrome: a double-blind, placebo-controlled trial. J Clin Psychopharmacol 22:31-39, 2002.

61. Scahill L, Leckman JF, Schultz RT, Katsovich L, Peterson BS. A placebo-controlled trial of risperidone in Tourette syndrome. Neurology 60:1130-1135, 2003.

62. Bruggeman R, van der Linden C, Buitelaar JK, Gericke GS, Hawkridge SM, Temlett JA. Risperidone versus pimozide in Tourette's syndrome: a comparative double-blind parallel group study. J Clin Psychiatry 62:50-56, 2001.

63. Gilbert DL, Batterson JR, Sethuraman G, Sallee FR. Tic reduction with risperidone versus pimozide in a randomized, doubleblind, crossover trial. J Am Acad Child Adolesc Psychiatry 43: 206-214, 2004

64. Gaffney GR, Perry PJ, Lund BC, Bever-Stille KA, Arndt S, Kuperman S. Risperidone versus clonidine in the treatment of children and adolescents with Tourette's syndrome. J Am Acad Child Adolesc Psychiatry 41:330-336, 2002.

65. Budman CL, Gayer A, Lesser M, Shi Q, Bruun RD. An openlabel study of the treatment efficacy of olanzapine for Tourette's disorder. J Clin Psychiatry 62:290-294, 2001.

66. Stamenkovic M, Schindler SD, Aschauser HN, DeZwaan M, Willinger U, Resinger E et al. Effective open-label treatment of Tourette's disorder with olanzapine. Int Clin Psychopharmacol 15:23-28, 2000.

67. Sallee FR, Kurlan R, Goetz CG, Singer H, Scahill L, Law G et al Ziprasidone treatment of children and adolescents with Tourette's syndrome: a pilot study. J Am Acad Child Adolesc Psychiatry 39:292-299, 2000.

68. Mukaddes NM, Abali O. Quetiapine treatment of children and adolescents with Tourette's disorder. J Child Adolesc Psychopharmacol 13:295-299, 2003.

69. Kastrup A, Schlotter W, Plewnia C, Bartels M. Treatment of tics in Tourette syndrome with aripiprazole. J Clin Psychopharmacol 25:94-96, 2005.

70. Eggers $\mathrm{CH}$, Rothenberger A, Berghaus U. Clinical and neurobiological findings in children suffering from tic disease following treatment with tiapride. Eur Arch Psychiatry Neurol Sci 237:223229, 1988.

71. Robertson MM, Schnieden V, Lees AJ. Management of Gilles de la Tourette syndrome using sulpiride. Clin Neuropharmacol 3:229-235, 1990.

72. Bruun RD. Subtle and unrecognized side effects of neuroleptic treatment in children with Tourette's disorder. Am J Psychiatry 145:621-624, 1988.

73. Allison DB, Casey DE. Antipsychotic-induced weight gain: a review of the literature. J Clin Psychiatry 62:22-31, 2001.

74. Martin A, Scahill L, Anderson GM, Aman M, Arnold LE, McCracken $\mathrm{J}$ et al. Weight and leptin changes among risperidonetreated youths with autism: 6-month prospective data. Am J Psychiatry 161:1125-1127, 2004.

75. Meyer JM, Koro CE. The effects of antipsychotic therapy on serum lipids: a comprehensive review. Schizophr Res 70:1-17, 2004.

76. Singer HS. The treatment of tics. Cur Neurol Neurosci Rep 1:195-202, 2001

77. Desta Z, Kerbusch T, Flockhart DA. Effect of clarithromycin on the pharmacokinetics and pharmacodynamics of pimozide in healthy poor and extensive metabolizers of cytochrome P450 2D6 (CYP2D6). Clin Pharmacol Ther 65:10-20, 1999.

78. Zareba W, Lin DA. Antipsychotic drugs and QT interval prolongation. Psychiatr Q 74:291-306, 2003.

79. U.S. Food and Drug Administration. NDA 20-825 approval letter and labeling for ziprasione. Available at: http://www.fda.gov/ cder/foi/label, 2001. Accessed March 2004.

80. Blair J, Scahill L, State M, Martin A. Electrocardiographic changes in children and adolescents treated with ziprasidone: a prospective study. J Am Acad Child Adolesc Psychiatry 44:7379, 2005.

81. Cohen DJ, Young JG, Nathanson JA, Shaywitz BA. Clonidine in Tourette's syndrome. Lancet 2:551-553, 1979.

82. American Academy of Child and Adolescent Psychiatry. Practice parameters for the assessment and treatment of children, adolescents, and adults with attention-deficit hyperactivity disorder. J Am Acad Child Adolesc Psychiatry 36:85S-121S, 1997.

83. Gutgesell H, Atkins D, Barst R, Buck M, Franklin W, Humes R et al. Cardiovascular monitoring of children and adolescents receiving psychotropic drugs: a statement for healthcare professionals from the Committee on Congenital Cardiac Defects, Council on Cardiovascular Disease in the Young, American Heart Association. Circulation 99:979-982, 1999.

84. Leckman JF, Ort S, Caruso KA, Anderson GM, Riddle MA, Cohen DJ. Rebound phenomena in Tourette's syndrome after abrupt withdrawal of clonidine. Arch Gen Psychiatry 43: 1168-1176, 1986.

85. Scahill L, Chappell PB, Kim YS, Schultz RT, Katsovich L, Shepherd E et al. Guanfacine in the treatment of children with tic disorders and ADHD: a placebo-controlled study. Am J Psychiatry 158:1067-1074, 2001 
86. Cummings DD, Singer HS, Krieger M, Miller TL, Mahone EM. Neuropsychiatric effects of guanfacine in children with mild Tourette syndrome: a pilot study. Clin Neuropharmacol 25:325$332,2002$.

87. Kurlan R, Como PG, Deeley C, McDermott M, McDermott MP. A pilot controlled study of fluoxetine for obsessive-compulsive symptoms in children with Tourette's syndrome. Clin Neuropharmacol 16:167-172, 1993.

88. Scahill L, Riddle MA, King RA, Hardin MT, Rasmusson A, Makuch RW et al. Fluoxetine has no marked effect on tic symptoms in patients with Tourette's syndrome: a double-blind placebo-controlled study. J Child Adolesc Psychopharmacol 7:75, 1997.

89. Jankovic J, Orman J. Tetrabenazine therapy of dystonia, chorea, tics, and other dyskinesias. Neurology 38:391-394, 1988.

90. Jankovic J, Beach J. Long-term effects of tetrabenazine in hyperkinetic movement disorders. Neurology 48:358-362, 1997.

91. Lipinski JF, Sallee FR, Jackson C, Sethuraman G. Dopamine agonist treatment of Tourette disorder in children: results of an open-label trial of pergolide. Mov Disord 12:402-407, 1997.

92. Gilbert DL, Sethuraman G, Sine L, Peters S, Sallee FR. Tourette's syndrome improvement with pergolide in a randomized, double-blind, crossover trial. Neurology 54:1310-1315, 2000.

93. Gilbert DL, Dure L, Sethuraman G, Raab D, Lane J, Sallee FR. Tic reduction with pergolide in a randomized controlled trial in children. Neurology 60:606-611, 2003.

94. Goetz CG, Stebbins GT, Thelen JA. Talipexole and adult Gilles de la Tourette's syndrome: double-blind, placebo-controlled clinical trial. Mov Disord 9:315-317, 1994.

95. Awaad Y. Tics in Tourette syndrome: new treatment options. J Child Neurol 14:316-319, 1999.

96. Jankovic J. Botulinum toxin in the treatment of dystonic tics. Mov Disord 9:347-349, 1994.

97. Kwak CH, Hanna PA, Jankovic J. Botulinum toxin in the treatment of tics. Arch Neurol 57:1190-1193, 2000.

98. Marras C, Andrews D, Sime E, Lang AE. Botulinum toxin for simple motor tics: a randomized, double-blind, controlled clinical trial. Neurology 56:605-610, 2001.

99. Porta M, Maggioni G, Ottaviani F, Schindler A. Treatment of phonic tics in patients with Tourette's syndrome using botulinum toxin type A. Neurol Sci 24:420-423, 2004.

100. Gonce M, Barbeau A. Seven cases of Gilles de la Tourette's syndrome: partial relief with clonazepam. A pilot study. Can J Neurol Sci 3:279-283, 1977.

101. Steingard RJ, Goldberg M, Lee D, DeMaso DR. Adjunctive clonazepam treatment of tic symptoms in children with comorbid tic disorders and ADHD. J Am Acad Child Adolesc Psychiatry 33:394-399, 1994.

102. Graae F, Milner J, Rizzotto L, Klein RG. Clonazepam in childhood anxiety disorders. J Am Acad Child Adolesc Psychiatry 33:372-376, 1994.

103. Singer HS, Wendlandt J, Krieger M, Giuliano J Baclofen treatment in Tourette syndrome: a double-blind, placebo-controlled, crossover trial. Neurology 56:599-604, 2001.

104. Abuzzahab FS, Brown VL. Control of Tourette's syndrome with topiramate. Am J Psychiatry 158:968, 2001.

105. Awaad Y, Michon AM, Minarik S. Use of levetiracetam to treat tics in children and adolescents with Tourette syndrome. Mov Disord 20:714-718, 2005.

106. Fraunfelder FW, Fraunfelder FT. Adverse ocular drug reactions recently identified by the National Registry of Drug-Induced Ocular Side Effects. Ophthalmology 111:1275-1279, 2004.

107. Sanberg PR, McConville BJ, Fogelson HM, Manderscheid PZ, Parker KW, Blythe MM et al. Nicotine potentiates the effects of haloperidol in animals and in patients with Tourette syndrome. Biomed Pharmacother 43:19, 1989.

108. McConville BJ, Sanberg PR, Fogelson MH, King J, Cirino P, Parker KW et al. The effects of nicotine plus haloperidol compared to nicotine only and placebo nicotine only in reducing tic severity and frequency in Tourette's disorder. Biol Psychiatry 15:832-840, 1992.
109. Silver AA, Shytle RD, Philipp MK, Wilkinson BJ, McConville B, Sanberg PR. Transdermal nicotine and haloperidol in Tourette's disorder: a double-blind placebo-controlled study. J Clin Psychiatry 62:707-714, 2001.

110. Shytle RD, Silver AA, Sheehan KH, Sheehan DV, Sanberg PR. Neuronal nicotinic receptor inhibition for treating mood disorders: preliminary controlled evidence with mecamylamine. Depress Anxiety 16:89-92, 2002.

111. Silver AA, Shytle RD, Sheehan KH, Sheehan DV, Ramos A, Sanberg PR. Multicenter, double-blind, placebo-controlled study of mecamylamine monotherapy for Tourette's disorder. $J \mathrm{Am}$ Acad Child Adolesc Psychiatry 40:1103-1110, 2001.

112. Peterson BS, Zhang H, Bondi C, Naftolin F, Leckman JF. A double-blind, placebo-controlled, crossover trial of an antiandrogen in the treatment of Tourette's syndrome. J Clin Psychopharmacol 18:324-331, 1998.

113. Leonard HL, Swedo SE, Rapoport JL, Koby EV, Lenane MC, Cheslow DL et al. Treatment of obsessive compulsive disorder with clomipramine and desipramine in children and adolescents. Arch Gen Psychiatry 46:1088-1092, 1989.

114. DeVeaugh-Geiss J, Katz R, Landau P, Goodman W, Rasmussen $\mathrm{S}$. Clinical predictors of treatment response in obsessive compulsive disorder: exploratory analyses from multicenter trials of clomipramine. Psychopharmacol Bull 26:54-59, 1990.

115. DeVeaugh-Geiss J, Moroz G, Biederman J, Cantwell D, Fontaine $\mathrm{R}$, Greist JH et al. Clomipramine hydrochloride in childhood and adolescent obsessive-compulsive disorder: a multicenter trial J Am Acad Child Adolesc Psychiatry 31:45-49, 1992.

116. Kaplan A, Hollander E. A review of pharmacologic treatments for obsessive-compulsive disorder. Psychiatr Serv 54:1111-1118, 2003.

117. Jenike MA. Clinical practice. Obsessive-compulsive disorder. N Engl J Med 350:259-265, 2004.

118. Montgomery SA, Kasper S, Stein DJ, Bang Hedegaard K, Lemming OM. Citalopram $20 \mathrm{mg}, 40 \mathrm{mg}$ and $60 \mathrm{mg}$ are all effective and well tolerated compared with placebo in obsessive-compulsive disorder. Int Clin Psychopharmacol 16:75-86, 2001.

119. March JS, Biederman J, Wolkow R, Safferman A, Mardekian J, Cook EH et al. Sertraline in children and adolescents with obsessive-compulsive disorder: a multicenter randomized controlled trial. JAMA 280:1752-1156, 1998.

120. Geller DA, Hoog SL, Heiligenstein JH, Ricardi RK, Tamura R, Kluszynski S et al. Fluoxetine Pediatric OCD Study Team. Fluoxetine treatment for obsessive-compulsive disorder in children and adolescents: a placebo-controlled clinical trial. J Am Acad Child Adolesc Psychiatry 40:773-779, 2001.

121. Riddle MA, Reeve EA, Yaryura-Tobias JA, Yang HM, Claghorn $\mathrm{JL}$, Gaffney $\mathrm{G}$ et al. Fluvoxamine for children and adolescents with obsessive-compulsive disorder: a randomized, controlled, multicenter trial. J Am Acad Child Adolesc Psychiatry 40:222229, 2001.

122. Liebowitz MR, Turner SM, Piacentini J, Beidel DC, Clarvit SR, Davies SO et al. Fluoxetine in children and adolescents with OCD: a placebo-controlled trial. J Am Acad Child Adolesc Psychiatry 41:1431-1438, 2002.

123. Geller DA, Wagner KD, Emslie G, Murphy T, Carpenter DJ, Wetherhold E et al. Paroxetine treatment in children and adolescents with obsessive-compulsive disorder: a randomized, multicenter, double-blind, placebo-controlled trial. J Am Acad Child Adolesc Psychiatry 43:1387-1396, 2004.

124. Pediatric OCD Treatment Study (POTS) Team. Cognitive-behavior therapy, sertraline, and their combination for children and adolescents with obsessive-compulsive disorder: The Pediatric OCD Treatment Study (POTS) randomized controlled trial. JAMA 292:1969-1976, 2004.

125. Riddle MA, King RA, Hardin MT, Scahill L, Ort SI, Leckman JF. Behavioral side effects of fluoxetine. J Child Adolesc Psychopharmacol 3:193-198, 1991.

126. U.S. Food and Drug Administration. Labeling Change Request Letter for Antidepressant Medications. Available at: http://www. fda.gov/cder/drug/antidpressants/SSRI labeling, Accessed October 15, 2004.

127. King RA, Riddle MA, Chappell PB, Hardin MT, Anderson GM, 
Lombroso $\mathrm{P}$ et al. Emergence of self-destructive phenomena in children and adolescents during fluoxetine treatment. J Am Acad Child Adolesc Psychiatry 30:179-186, 1991.

128. Oesterheld JR. Erythromycin and clomipramine: noncompetitive inhibition of demethylation. J Child Adolesc Psychopharmacol 6:211-213, 1996.

129. Rosenbaum JF, Fava M, Pava JA, McCarthy MK, Steingard RJ, Bouffides E. Anger attacks in unipolar depression. Part 2: Neuroendocrine correlates and changes following fluoxetine treatment. Am J Psychiatry 150:1164-1168, 1993.

130. Hollander E, Bienstock CA, Koran LM, Pallanti S, Marazziti D, Rasmussen SA, et al. Refractory obsessive-compulsive disorder: state-of-the-art treatment. J Clin Psychiatry 63:20-29, 2002.

131. Varley CK. Sudden death related to selected tricyclic antidepressants in children: epidemiology, mechanisms and clinical implications. Paediatr Drugs 3:613-627, 2001.

132. Expert Consensus Panel for Obsessive-Compulsive Disorder. Treatment of obsessive-compulsive disorder. J Clin Psychiatry 58:2-72, 1997.

133. Warneke LB. The use of intravenous chlorimipramine in the treatment of obsessive compulsive disorder. Can J Psychiatry 29:135-141, 1984.

134. Koran LM, Pallanti S, Paiva RS, Quercioli L. Pulse loading versus gradual dosing of intravenous clomipramine in obsessivecompulsive disorder. Eur Neuropsychopharmacol 8:121-126, 1998.

135. Sallee FR, Koran LM, Pallanti S, Carson SW, Sethuraman G. Intravenous clomipramine challenge in obsessive-compulsive disorder: predicting response to oral therapy at eight weeks. Biol Psychiatry 44:220-227, 1998.

136. Greenhill LL, Abikoff HB, Arnold LE, Cantwell DP, Conners $\mathrm{CK}$, Elliott $\mathrm{G}$ et al. Medication treatment strategies in the MTA study: relevance to clinicians and researchers. J Am Acad Child Adolesc Psychiatry 35:1304-1313, 1996.

137. Elia J, Borcherding BG, Rapoport JL, Keysor CS. Methylphenidate and dextroamphetamine treatments of hyperactivity: are there true non-responders? Psychiatr Res 36:141-155, 1991.

138. Erenberg G, Cruse RP, Rothner AD. Gilles de la Tourette's syndrome: effects of stimulant drugs. Neurology 35:1346-1348, 1985.

139. Golden GS. Gilles de la Tourette's syndrome following methylphenidate administration. Dev Med Child Neurol 16:76-78, 1974.

140. Lowe TL, Cohen DJ, Detlor J, Kremenitzer MW, Shaywitz BA. Stimulant medications precipitate Tourette's syndrome. JAMA 26:1729-1731, 1992.

141. Lipkin PH, Goldstein IJ, Adesman AR. Tics and dyskinesias associated with stimulant treatment in attention-deficit hyperactivity disorder. Arch Pediatr Adolesc Med 148:859-861, 1994.

142. Riddle MA, Lynch KA, Scahill L. Methylphenidate discontinuation during long-term treatment of children with Tourette's disorder and attention deficit hyperactivity disorder: a pilot study. J Child Adolesc Psychopharmacol 5:205-214, 1995.

143. Varley CK, Vincent J, Varley P, Calderon R. Emergence of tics in children with attention deficit hyperactivity disorder treated with stimulant medications. Comp Psychiatry 42:228-233, 2001.

144. Barkley RA, McMurray MB, Edelbrock CS, Robbins K. Side effects of methylphenidate in children with attention deficit hyperactivity disorder: a systemic, placebo-controlled evaluation. Pediatrics 86:184-192, 1992.

145. Borcherding BG, Keysor CS, Rapoport JL, Elia J, Amass J. Motor/vocal tics and compulsive behaviors on stimulant drugs: is there a common vulnerability? Psychiatry Res 33:83-94, 1990.

146. Castellanos FX, Geidd JN, Elia J. Controlled stimulant treatment of ADHD and comorbid Tourette's syndrome: effects of stimulant and dose. J Am Acad Child Adolesc Psychiatry 36:589-596, 1997.

147. Gadow KD, Sverd J, Sprafkin J, Nolan EE, Ezor SN. Efficacy of methylphenidate for attention-deficit hyperactivity disorder in children with tic disorder. Arch Gen Psychiatry 52:444-455, 1995.

148. Tourette Syndrome Study Group. Treatment of ADHD in children with tics: a randomized controlled trial. Neurology 58:527$536,2002$.
149. Gadow KD, Sverd J, Sprafkin J, Nolan EE, Grossman S. Longterm methylphenidate therapy in children with comorbid attention-deficit hyperactivity dsorder and chronic multiple tic disorder. Arch Gen Psychiatry 56:330-336, 1999.

150. Law SF, Schachar RJ. Do typical clinical doses of methylphenidate cause tics in children treated for attention-deficit hyperactivity disorder? J Am Acad Child Adolesc Psychiatry 38:944-951, 1999.

151. Biederman J, Baldessarini RJ, Wright V, Knee D, Harmatz JS. A double-blind placebo controlled study of desipramine in the treatment of ADD. I. Efficacy. J Am Acad Child Adolesc Psychiatry 28:777-784, 1989.

152. Singer H, Brown J, Quaskey S, Rosenberg LA, Mellits ED, Denckla MB. The treatment of attention-deficit hyperactivity disorder in Tourette's syndrome: a double-blind placebo-controlled study with clonidine and desipramine. Pediatrics 95:7481, 1995.

153. Spencer T, Biederman J, Coffey B, Geller D, Crawford M, Bearman SK et al. A double-blind comparison of desipramine and placebo in children and adolescents with chronic tic disorder and comorbid attention-deficit/hyperactivity disorder. Arch Gen Psychiatry 59:649-656, 2002.

154. Riddle MA, Geller B, Ryan N. Another sudden death in a child treated with desipramine. J Am Acad Child Adolesc Psychiatry 32:792-797, 1993.

155. Barrickman L, Perry P, Allen A, Kuperman S, Arndt S, Herrmann $\mathrm{K}$, et al. Buproprion versus methylphenidate in the treatment of attention-deficit hyperactivity disorder. J Am Acad Child Adolesc Psychiatry 34:649-657, 1995.

156. Casat CD, Pleasants DZ, Van Wyck Fleet J. A double-blind trial of bupropion in children with attention deficit disorder. Psychopharmacol Bull 23:120-122, 1987.

157. Casat CD, Pleasants DZ, Schroeder DH, Parler DW. Bupropion in children with attention deficit disorder. Psychopharmacol Bull 25:198-201, 1989.

158. Conners CK, Casat CD, Gualtieri CT, Weller E, Reader M, Reiss A et al. Bupropion hydrochloride in attention deficit disorder with hyperactivity. J Am Acad Child Adolesc Psychiatry 34:1314$1321,1996$.

159. Spencer T, Biederman J, Steingard R, Wilens T. Bupropion exacerbates tics in children with attention-deficit hyperactivity disorder and Tourette's syndrome. J Am Acad Child Adolesc Psychiatry 32:211-214, 1993.

160. Belson MG, Kelley TR. Bupropion exposures: clinical manifestations and medical outcome. J Emerg Med 23:223-230, 2002.

161. Buitelaar JK, van der Gaag RJ, Swaab-Barneveld H, Kuiper M. Pindolol and methylphenidate in children with attention-deficit hyperactivity disorder: clinical efficacy and side-effects. $J$ Child Psychol Psychiatry 37:587-595, 1996.

162. Feigin A, Kurlan R, McDermott MP, Beach J, Dimitsapulos T, Brower CA et al. A controlled trial of deprenyl in children with Tourette's syndrome and attention deficit hyperactivity disorder. Neurology 46:965-968, 1996.

163. Hunt RD, Minderaa RB, Cohen DJ. Clonidine benefits children with attention deficit disorder and hyperactivity: report of a double-blind placebo-crossover therapeutic trial. J Am Acad Child Adolesc Psychiatry 24:617-629, 1985.

164. Connor DF, Barkely RA, Davis HT. A pilot study of methylphenidate, clonidine, or the combination in ADHD comorbid with aggressive oppositional defiant or conduct disorder. Clin Pediatr 39:15-25, 2000.

165. Rapport MD, Denney C, DuPaul GJ, Gardener M. Attention deficit disorder and methylphenidate: normalization rates, clinical effectiveness, and response prediction in 76 children. J Am Acad Child Adolesc Psychiatry 33:882-893, 1994.

166. Hunt RD, Arnsten AFT, Asbell MD. An open trial of guanfacine in the treatment of attention deficit hyperactivity disorder. $J \mathrm{Am}$ Acad Child Adolesc Psychiatry 34:50-54, 1995.

167. Horrigan JP, Barnhill LJ. Guanfacine for treatment of attentiondeficit hyperactivity disorder in boys. J Child Adolesc Psychopharmacol 5:215-223, 1995.

168. Chappell PB, Riddle MA, Scahill L, Lynch KA, Schultz R, Arnsten A et al. Guanfacine treatment of comorbid attention-deficit 
hyperactivity disorder in Tourette's syndrome: preliminary clinical experience. J Am Acad Child Adolesc Psychiatry 34:1140-1146, 1995.

169. Solanto MV, Arnsten AFT, Catellanos FX. Stimulant drugs and ADHD: basic and clinical neuroscience. New York: Oxford, 2001.

170. Sukhodolsky D, Scahill L, Zhang H, Peterson BS, King RA, Lombroso PJ et al. Disruptive behavior in children with Tourette's syndrome: association of ADHD comorbidity, tic severity, and functional impairment. J Am Acad Child Adolesc Psychiatry 42:98-105, 2003.

171. Michelson D, Faries D, Wernicke J, Kelsey D, Kendrick K, Sallee FR et al. Atomoxetine ADHD Study Group. Atomoxetine in the treatment of children and adolescents with attention-deficit/hyperactivity disorder: a randomized, placebo-controlled, dose-response study. Pediatrics 108:E83, 2001.

172. Michelson D, Allen AJ, Busner J, Casat C, Dunn D, Kratochvil C et al. Once daily atomoxetine treatment for children and adolescents with attention deficit hyperactivity disorder: a randomized, placebo-controlled study. Am J Psychiatry 159:1896, 2002.

173. Berthier ML, Kulisevsky J, Campos VM. Bipolar disorder in adult patients with Tourette's syndrome: a clinical study. Biol Psychiatry 43:364-370, 1998.

174. Comings BG, Comings DE. A controlled study of Tourette syndrome. V. Depression and mania. Am J Hum Genet 41:804-821, 1987.

175. Comings DE, Comings BG. A controlled study of Tourette syndrome. III. Phobias and panic attacks. Am J Hum Genet 41:761781, 1987.

176. Comings DE, Comings BG. A controlled family history study of Tourette's syndrome. III. Affective and other disorders. J Clin Psychiatry 51:288-291, 1990.

177. Coffey BJ, Biederman J, Smoller JW, Geller DA, Sarin P, Schwartz S et al. Anxiety disorders and tic severity in juveniles with Tourette's disorder. J Am Acad Child Adolesc Psychiatry 39:562-568, 2000.

178. Coffey BJ, Park KS. Behavioral and emotional aspects of Tourette syndrome. Neurol Clin 15:277-289, 1997.

179. Kerbeshian J, Burd L, Klug MG. Comorbid Tourette's disorder and bipolar disorder: an etiologic perspective. Am J Psychiatry 152:1646-1651, 1995.

180. Comings DE. Role of genetic factors in depression based on studies of Tourette syndrome and ADHD probands and their relatives. Am J Med Genet 60:111-121, 1995.

181. Palumbo D, Maughan A, Kurlan R. Hypothesis: III. Tourette syndrome is only one of several causes of a developmental basal ganglia syndrome. Arch Neurol 54:475-483, 1997.

182. King RA, Scahill L. Emotional and behavioral difficulties associated with Tourette syndrome. Adv Neurol 85:79-88, 2001.

183. Fava M, Rush AJ, Trivedi MH, Nierenberg AA, Thase ME, Sackeim HA et al. Background and rationale for the sequenced treatment alternatives to relieve depression $\left(\mathrm{STAR}^{*} \mathrm{D}\right)$ study. Psychiatr Clin North Am 26:457-494, 2003.

184. Emslie GJ, Mayes TL. Mood disorders in children and adolescents: psychopharmacological treatment. Biol Psychiatry 49:1082-1090, 2001.

185. Sachs GS. Decision tree for the treatment of bipolar disorder. J Clin Psychiatry 64:35-40, 2003.

186. Expert Consensus Guideline Series. Treatment of bipolar disorder. J Clin Psychiatry 57:3-88, 1996.

187. Gorman JM. Treating generalized anxiety disorder. J Clin Psychiatry 64:24-29, 2003.

188. Budman CL, Bruun RD, Park KS, Lesser M, Olson M. Explosive outbursts in children with Tourette's disorder. J Am Acad Child Adoles Psychiatry 39:1270-1276, 2000.

189. Freeman RD, Fast DK, Burd L, Kerbeshian J, Robertson MM, Sandor P. An international perspective on Tourette syndrome: selected findings from 3,500 individuals in 22 countries. Dev Med Child Neurol 42:436-447, 2000.

190. Bruun RD, Budman CL. Paroxetine treatment of episodic rages associated with Tourette's disorder. J Clin Psychiatry 59:581584, 1998.

191. Research Units on Pediatric Psychopharmacology (RUPP) Autism Network. Risperidone in children with autism for serious behavioral problems. N Engl J Med 347:314-321, 2002.

192. Aman MG, De Smedt G, Derivan A, Lyons B, Findling RL. Risperidone Disruptive Behavior Study Group. Double-blind, placebo-controlled study of risperidone for the treatment of disruptive behaviors in children with subaverage intelligence. Am J Psychiatry 159:1337-1346, 2002.

193. Donovan SJ, Stewart JW, Nunes EV, Quitkin FM, Parides M, Daniel W et al. Divalproex treatment for youth with explosive temper and mood lability: a double-blind, placebo-controlled crossover design. Am J Psychiatry 157:818-820, 2000.

194. Lombroso PJ, Scahill L, King RA, Lynch KA, Chappell PB, Peterson BS et al. Risperidone treatment of children and adolescents with chronic tic disorders: a preliminary report. J Am Acad Child Adolesc Psychiatry 34:1147-1152, 1995.

195. McDougle CJ, Goodman WK, Leckman JF, Lee NC, Heninger GR, Price LH. Haloperidol addition in fluvoxamine-refractory obsessive compulsive disorder: a double-blind, placebo-controlled study in patients with and without tics. Arch Gen Psychiatry 51:302-308, 1994.

196. McDougle CJ, Epperson CN, Pelton GH, Wasylink S, Price LH. A double-blind, placebo-controlled study of risperidone addition in serotonin reuptake inhibitor-refractory obsessive-compulsive disorder. Arch Gen Psychiatry 57:794-801, 2000.

197. Figueroa Y, Rosenberg DR, Birmaher B, Keshavan MS. Combination treatment with clomipramine and selective serotonin reuptake inhibitors for obsessive-compulsive disorder in children and adolescents. J Child Adolesc Psychopharmacol 8:61-67, 1998. 